\title{
Calculation of Neutron Production Rates and Spectra from Compounds of Actinides and Light Elements
}

\author{
Gennady Vlaskin ${ }^{\mathrm{a}}$ and Yuriy Khomiakov ${ }^{1}$ \\ ${ }^{1}$ ITCP, Innovation and Technology Centre for Proryv Project, Moscow, Russia
}

\begin{abstract}
The code NEDIS allows the calculation of neutron production rate and continuous energy spectra due to $(\alpha, \mathrm{n})$ reaction on $\mathrm{Li}, \mathrm{Be}, \mathrm{B}, \mathrm{C}, \mathrm{O}, \mathrm{F}, \mathrm{Ne}, \mathrm{Na} \mathrm{Mg}, \mathrm{Al}, \mathrm{Si}, \mathrm{P}, \mathrm{S}, \mathrm{Cl}, \mathrm{Ar}, \mathrm{K}$, and $\mathrm{Ca}$. It accounts for anisotropic angular distribution of neutrons of $(\alpha, n)$ reaction in centre-of- mass system and dimensions of alpha emitting source material particles. Spontaneous fission spectra are calculated with evaluated half-life, spontaneous fission branching, $v$ averaged per fission, and Watt spectrum parameters. The results of calculations by NEDIS can be used as input for Monte Carlo simulation for materials that will be used in radiation shielding and for underground neutron experiments
\end{abstract}

\section{Introduction}

The code NEDIS has been developed for simulation of neutron production rate and spectra due to $(\alpha, n)$ reactions and spontaneous fission for using in nondestructive assay of plutonium in technology process of nuclear fuel fabrication and reprocessing [1,2]. The development has required the accumulation and evaluation of measured and calculated $(\alpha, n)$-reaction cross-sections and angular neutron distributions for the individual levels of the residual nucleus, $\alpha$-particle stopping cross-section data and the actinides decay constants. Today the code library includes $(\alpha, n)$-reaction data for the light target nuclides in the Table 1 for alphaparticle energy less $9 \mathrm{MeV}$ [3]. The code library has $\alpha$ decay information for 58 heavy nuclides from ${ }^{210} \mathrm{~Pb}$ to ${ }^{254} \mathrm{Cf}$ and 36 actinides have the spontaneous fission mode.

The neutron production code NEDIS2.0 was benchmarked using the following data: experimental measurements of thick-target yields of $(\alpha, n)$-neutrons from $\mathrm{Be}, \mathrm{BeO}, \mathrm{BN}, \mathrm{C}, \mathrm{UC}, \mathrm{UO}_{2}, \mathrm{Mg}, \mathrm{Al}, \mathrm{Si}$ [4]; experimental data of thick-target neutron spectra of $(\alpha, n)$ reaction from $\mathrm{B}, \mathrm{C}, \mathrm{O}, \mathrm{Mg}, \mathrm{F}, \mathrm{Al}, \mathrm{Si}, \mathrm{Al}_{2} \mathrm{O}_{3}, \mathrm{SiO}_{2}$ measured in energy-tunable alpha-particle accelerator [5]; experimental measurements of thick-target $(\alpha, n)$-reaction yields and neutron spectra from compounds of actinides with light elements [6-8]. In this report we present some data of neutrons yields and spectra from $(\alpha, n)$-reactions and spontaneous fission.

\section{Calculation of neutron yields and energy spectra}

The heavy nuclides in materials produce $\mathrm{MeV} \alpha$ particles. These $\alpha$-particles interact with the nucleus in a

\footnotetext{
a Corresponding author: vlasking@ mail.ru
}

thick target of light elements and yield neutrons. The neutron yield is calculated by:

$$
Q\left(E_{\alpha}\right)=\int_{E_{t h}}^{E_{\alpha}} \frac{\sigma_{t o t}(E)}{\varepsilon(E)} d E
$$

where $E_{\text {th }}-$ is the energy of threshold, $E_{\alpha}$-is the initial energy of the $\alpha$-particle, $\varepsilon$-is atomic stopping power [9], $\sigma_{\text {tot }}$ total cross-section of the $(\alpha, n)$-reaction. For an arbitrary primary $\alpha$-particle spectrum the neutron yield is calculated by:

$$
Q=\int_{0}^{E_{\alpha, \max }} \frac{\sigma_{t o t}\left(E_{\alpha}\right)}{\varepsilon\left(E_{\alpha}\right)} P\left(E_{\alpha}\right) d E_{\alpha}
$$

where $\mathrm{P}\left(\mathrm{E}_{\alpha}\right)$ number of $\alpha$-particles with energy more than $\mathrm{E}_{\alpha}$.

\subsection{Method of $(\alpha, n)$ neutron spectrum calculation}

The differential neutron yield in the reaction $(\alpha, n)$ within the solid angle $\Omega^{*}$ in the centre-of-mass system (CMS) for an individual state of the residual nucleus is given by the expression

$$
d^{2} Q=\frac{1}{\varepsilon}\left(\frac{\partial \sigma\left(E_{\alpha}, \Omega^{*}\right)}{\partial \Omega^{*}}\right) d \Omega^{*} d E_{\alpha}
$$

where $\frac{\partial \sigma\left(E_{\alpha}, \Omega^{*}\right)}{\partial \Omega^{*}}$ is the differential reaction cross section, which is expediently expressed as an expansion in Legendre polynomials

$$
\frac{\partial \sigma\left(E_{\alpha}, \Omega^{*}\right)}{\partial \Omega^{*}}=\frac{\sigma^{\mathrm{int}}\left(E_{\alpha}\right)}{4 \pi}\left[1+\sum_{\ell} a_{\ell}\left(E_{\alpha}\right) P_{\ell}\left(\cos \theta^{*}\right)\right]
$$


Putting (4) to the (3) and after transformation from solid angle in the CMS to energy $E_{n}$ in laboratory system the differential neutron yield in the reaction $(\alpha, n)$ is obtained

$$
d^{2} Q=\frac{1}{\varepsilon} \frac{\sigma^{\text {int }}\left(E_{\alpha}\right)}{4 \pi}\left[1+\sum_{\ell} a_{\ell}\left(E_{\alpha}\right) P_{\ell}\left(\cos \theta^{*}\right)\right] I\left(E_{\alpha}\right) d E_{h} d E_{\alpha \alpha}(5)
$$

where $\mathrm{I}\left(\mathrm{E}_{\alpha}\right)$ Jacobian of the transformation is equal to

$$
\mathrm{I}\left(E_{\alpha}\right)=\frac{\partial \Omega^{*}}{\partial E_{n}}=2 \pi \frac{d\left(\cos \theta^{*}\right)}{d E_{n}}=\frac{4 \pi}{R\left(E_{\alpha}\right)}
$$

as the energy of neutron and $\cos \left(\theta^{*}\right)$ is coupled by the expression

$$
E_{n}=\frac{R\left(E_{\alpha}\right)}{4}\left(\gamma\left(E_{\alpha}\right)+\frac{1}{\gamma\left(E_{\alpha}\right)}+2 \cos \theta^{*}\right)
$$

where $\mathrm{R}\left(\mathrm{E}_{\alpha}\right)=\mathrm{E}_{\mathrm{n}}\left(\mathrm{E}_{\alpha}, 0^{\circ}\right)-\mathrm{E}_{\mathrm{n}}\left(\mathrm{E}_{\alpha}, 180^{\circ}\right)$, function $\gamma\left(E_{\alpha}\right)$ is the ratio of velocity CMS in laboratory system to velocity of neutron in CMS. After all appropriate transformation and integration with respect to $\mathrm{E}_{\alpha}$, the neutron spectrum of the $(\alpha, n)$-reaction is obtained

$$
\frac{d Q\left(E_{n}\right)}{d E_{n}}=\int_{X\left(E_{n}\right)}^{Y\left(E_{n}\right)} \frac{\sigma^{\mathrm{int}}\left(E_{\alpha}\right)}{\mathcal{\varepsilon}\left(E_{\alpha}\right) R\left(E_{\alpha}\right)}\left[1+\sum_{\ell \geq 1} a_{\ell}\left(E_{\alpha}\right) P_{\ell}\left(\cos \theta^{*}\right)\right] d E_{\alpha}
$$

(8)

The limits of integration $\mathrm{X}\left(\mathrm{E}_{\mathrm{n}}\right)$ and $\mathrm{Y}\left(\mathrm{E}_{\mathrm{n}}\right)$ are determined by the kinematics of the reaction [10].

The neutron spectrum of a mixture of elements may be determined from the formula for an arbitrary primary $\alpha$-particle spectrum by

$$
\frac{d Q\left(E_{n}\right)}{d E_{n}}=\sum_{i, j, k} \int_{X_{i, j, k}\left(E_{n}\right)}^{Y_{i, j, k}\left(E_{n}\right)} \frac{\sigma_{i, j, k}^{\mathrm{jnt}}\left(E_{\alpha}\right) f_{i, j, k}\left(E_{n}, E_{\alpha}\right) R A T_{j, k}}{\left.\left[E_{\alpha}\right)+\sum_{\beta=1, \beta \neq k}^{L} \frac{N_{\beta} \varepsilon_{\beta}}{N_{k}}\right] R_{i, j, k}\left(E_{\alpha}\right)} P\left(E_{\alpha}\right) d E_{\alpha}
$$

(9)

where $\mathrm{i}$ is the level of the residual nucleus as a result of reaction with the $\mathrm{j}$-th isotope of the $\mathrm{k}$-th element; $\mathrm{j}$ is the isotope of the $\mathrm{k}$-th element participating in the $(\alpha, n)$ reaction; $k$ is the element of the $j$-th isotope which is involved in the $(\alpha, n)$-reaction; $\beta$ is a particular element in the mixture, $1 \leq \beta \leq \mathrm{L}$; $\mathrm{L}$ is the number of elements in the mixture; $\mathrm{N}_{\beta}, \mathrm{N}_{\mathrm{k}}$ are the numbers of atoms of the corresponding element in unit volume of mixture; $\operatorname{RAT}_{\mathrm{j}, \mathrm{k}}$ is the ratio of the number of nuclei of isotope $j$ which involved in the $(\alpha, n)$-reaction to the total number of nuclei of element $\mathrm{k}$ or atomic abundance [11]; $\mathrm{P}\left(\mathrm{E}_{\alpha}\right)$ is the number of $\alpha$-particles with energy more than $E_{\alpha}$ in an arbitrary primary $\alpha$-particle spectrum; $f_{i, j, k}\left(E_{n}, E_{\alpha}\right)$ is the angle component expansion of cross-section in Legendre polynomials. The limits of integration are determined by the kinematics of the reaction to the ground state and each of the excited states of the residual nucleus.

Gauss method [12] with 20 knots is used with prescribed accuracy for the calculation equation (9) in the code NEDIS2.0. The code such as SOURCES4C [13] calculates the neutron yield of many sources assuming isotropy of neutron emission and sometimes homogeneity in constitution. SOURCES performs trapezoidal intergration in each alpha particle user discretised energy group to obtain the $(\alpha, n)$ spectrum contributions and total

\begin{tabular}{|c|c|c|c|c|}
\hline Nuclide & $\begin{array}{c}\text { Atomic } \\
\text { abundance, } \\
{[11]}\end{array}$ & Reaction & $\begin{array}{c}\text { Reaction } \\
\text { threshold, } \\
\mathrm{MeV}\end{array}$ & $\begin{array}{l}\text { Number of levels, } \\
\text { (last level energy) }\end{array}$ \\
\hline${ }^{6} \mathrm{Li}$ & 7.59 & ${ }^{6} \operatorname{Li}(\alpha, n){ }^{9} B$ & 6.619 & $1(0.0)$ \\
\hline${ }^{7} \mathrm{Li}$ & 92.41 & ${ }^{7} \operatorname{Li}(\alpha, n){ }^{10} B$ & 4.38 & $4(2.154)$ \\
\hline${ }^{9} \mathrm{Be}$ & 100 & ${ }^{9} \mathrm{Be}(\alpha, n){ }^{12} \mathrm{C}$ & 0 & $4(9.611)$ \\
\hline${ }^{9} \mathrm{Be}$ & 100 & ${ }^{9} \mathrm{Be}(\alpha, n) 3^{4} \mathrm{He}$ & 2.272 & $2(0.42)$ \\
\hline${ }^{10} B$ & 19.9 & ${ }^{10} B(\alpha, n)^{13} N$ & 0 & $9(8.00)$ \\
\hline${ }^{11} B$ & 80.1 & ${ }^{11} B(\alpha, n){ }^{14} N$ & 0 & $11(7.03)$ \\
\hline${ }^{13} \mathrm{C}$ & 1.108 & ${ }^{13} \mathrm{C}(\alpha, n){ }^{16} \mathrm{O}$ & 0 & $5(7.117)$ \\
\hline${ }^{14} \mathrm{~N}$ & 99.632 & ${ }^{14} N(\alpha, n){ }^{17} F$ & 6.088 & $2(0.495)$ \\
\hline${ }^{17} \mathrm{O}$ & 0.038 & ${ }^{17} \mathrm{O}(\alpha, n){ }^{20} \mathrm{Ne}$ & 0 & $5(5.618)$ \\
\hline${ }^{18} \mathrm{O}$ & 0.205 & ${ }^{18} \mathrm{O}(\alpha, n){ }^{2 l} \mathrm{Ne}$ & 0.851 & $7(5.337)$ \\
\hline${ }^{19} \mathrm{~F}$ & 100 & ${ }^{19} \mathrm{~F}(\alpha, n){ }^{22} \mathrm{Na}$ & 2.36 & $29(5.174)$ \\
\hline${ }^{2 l} \mathrm{Ne}$ & 0,27 & ${ }^{2 l} \mathrm{Ne}(\alpha, n){ }^{24} \mathrm{Mg}$ & 0 & $5(5.236)$ \\
\hline${ }^{22} \mathrm{Ne}$ & 9,25 & ${ }^{22} \mathrm{Ne}(\alpha, n){ }^{25} \mathrm{Mg}$ & 0,57 & $9(3.405)$ \\
\hline${ }^{23} \mathrm{Na}$ & 100 & ${ }^{23} \mathrm{Na}(\alpha, n)^{26} \mathrm{Al}$ & 3.485 & $29(4.22)$ \\
\hline${ }^{25} \mathrm{Mg}$ & 10.00 & ${ }^{25} \mathrm{Mg}(\alpha, n)^{28} \mathrm{Si}$ & 0 & $9(7.80)$ \\
\hline${ }^{26} \mathrm{Mg}$ & 11.01 & ${ }^{26} \mathrm{Mg}(\alpha, n)^{29} \mathrm{Si}$ & 0 & $5(3.069)$ \\
\hline${ }^{27} \mathrm{Al}$ & 100 & ${ }^{27} \mathrm{Al}(\alpha, n){ }^{30} \mathrm{P}$ & 3.027 & $20(4.80)$ \\
\hline${ }^{29} \mathrm{Si}$ & 4.6832 & ${ }^{29} \mathrm{Si}(\alpha, n){ }^{32} S$ & 1.736 & $10(5.80)$ \\
\hline${ }^{30} \mathrm{Si}$ & 3.0872 & ${ }^{30} \mathrm{Si}(\alpha, n){ }^{33} S$ & 3.959 & $11(4.21)$ \\
\hline${ }^{31} P$ & 100 & ${ }^{31} \mathrm{P}(\alpha, n){ }^{34} \mathrm{Cl}$ & 6.380 & $1(0.0)$ \\
\hline${ }^{33} S$ & 0.76 & ${ }^{33} \mathrm{~S}(\alpha, n)^{36} \mathrm{Ar}$ & 2.244 & $2(1.970)$ \\
\hline${ }^{34} S$ & 4.29 & ${ }^{34} S(\alpha, n){ }^{37} A r$ & 5.176 & $1(0.0)$ \\
\hline${ }^{35} \mathrm{Cl}$ & 75.78 & ${ }^{35} \mathrm{Cl}(\alpha, n)^{38} \mathrm{~K}$ & 6.530 & $1(0.0)$ \\
\hline${ }^{37} \mathrm{Cl}$ & 24.22 & ${ }^{37} \mathrm{Cl}(\alpha, n)^{40} \mathrm{~K}$ & 4.292 & $21(3.52)$ \\
\hline${ }^{38} \mathrm{Ar}$ & 0.0629 & ${ }^{38} \mathrm{Ar}(\alpha, n){ }^{4 l} \mathrm{Ca}$ & 5.774 & $1(0.0)$ \\
\hline${ }^{40} \mathrm{Ar}$ & 99.604 & ${ }^{40} \mathrm{Ar}(\alpha, n){ }^{43} \mathrm{Ca}$ & 2.506 & $15(5.70)$ \\
\hline${ }^{41} K$ & 6.73 & ${ }^{41} K(\alpha, n){ }^{44} S c$ & 3.727 & 21(3.10) \\
\hline${ }^{42} \mathrm{Ca}$ & 0.647 & ${ }^{42} \mathrm{Ca}(\alpha, n)^{45} \mathrm{Ti}$ & 5.683 & $1(0.0)$ \\
\hline${ }^{43} \mathrm{Ca}$ & 0.135 & ${ }^{43} \mathrm{Ca}(\alpha, n)^{46} \mathrm{Ti}$ & 0.0 & $1(0.0)$ \\
\hline${ }^{44} \mathrm{Ca}$ & 2.086 & $\left.{ }^{44} \mathrm{Ca}(\alpha, n)\right)^{47} \mathrm{Ti}$ & 2.381 & $1(0.0)$ \\
\hline${ }^{46} \mathrm{Ca}$ & 0.004 & ${ }^{46} \mathrm{Ca}(\alpha, n)^{49} \mathrm{Ti}$ & 0.241 & $1(0.0)$ \\
\hline${ }^{48} \mathrm{Ca}$ & 0.178 & ${ }^{48} \mathrm{Ca}(\alpha, n)^{51} \mathrm{Ti}$ & 0.144 & $1(0.0)$ \\
\hline
\end{tabular}
spectrum. It is restricted to alpha energies up to $6.5 \mathrm{MeV}$.
The code as USD [14] did not compute the continuous retardation of the $\alpha$-particles correctly.

Table 1. Light nuclides data available in NEDIS-2.0 library

\subsection{Method of neutron spectrum calculation of spontaneous fission (SF)}

Spontaneous fission spectra are calculated with evaluated half-life, spontaneous fission branching, $v$ averaged per fission, and Watt spectrum parameters. The currently available nuclear data relevant to the spontaneous fission neutron yields are presented in [15]. Neutron multiplicities were similarly taken from [15]. 
The energy spectrum of neutrons emitted by the spontaneous fission of 36 actinides is described by a Watt formula: $e^{-E / a} \cdot \sinh (b \cdot E)^{1 / 2}$, where $E$ is the neutron energy, and $\mathbf{a}$ and $\mathbf{b}$ are the radionuclide-specific fission parameters obtained from the NEDIS2.0 data library. The parameter a (temperature) deals with the neutron multiplicity by the Terrell formula [16] with our new coefficients for spontaneous fission

$$
\mathbf{a}=0,48+0,2\left(1+\bar{v}_{S F}\right)^{1 / 2}
$$

The parameter $\mathbf{b}$ is determined by this temperature and average kinetic energy per nucleon of spontaneus fission products which is equal to $E_{f}=0,76 \mathrm{MeV}$ in NEDIS2.0 data library

$$
\mathbf{b}=4 \mathrm{E}_{\mathrm{f}} / \mathbf{a}^{2}=3,04 / \mathbf{a}^{2}
$$

In this case the average energy of neuron spectrum of spontaneous fission is equal to

$$
\begin{aligned}
<E> & =E_{f}+(3 / 2) * a=1,48+0,3 *\left(1+\bar{v}_{S F}\right)^{1 / 2}(12) \\
\text { or } & <E>=1,5 a+0,25 a^{2} b
\end{aligned}
$$

The parameters of some nuclides are presented in the Tables 2 and 3 in comparison with [17-19].

Table 2. Radionuclide-specific fission parameters

\begin{tabular}{|c|c|c|c|}
\hline \multirow{2}{*}{ Nuclide } & \multicolumn{3}{|c|}{ The parameter a } \\
\cline { 2 - 4 } & NEDIS & SOURCES & {$[19]$} \\
\hline $\mathrm{U}-238$ & 0.827 & 0.6483 & 0.8366 \\
\hline $\mathrm{Pu}-240$ & 0.8355 & 0.795 & 0.7989 \\
\hline $\mathrm{Cm}-248$ & 0.8855 & 0.8084 & - \\
\hline $\mathrm{Cf}-252$ & 0.916 & 1.025 & 1.025 \\
\hline Th-232 & 0.796 & 0.5934 & - \\
\hline \multicolumn{3}{|c|}{ The parameter b } \\
\hline $\mathrm{U}-238$ & 4.445 & 6.811 & 4.339 \\
\hline $\mathrm{Pu}-240$ & 4.335 & 4.689 & 4.903 \\
\hline $\mathrm{Cm}-248$ & 3.877 & 4.536 & - \\
\hline $\mathrm{Cf}-252$ & 3.623 & 2.926 & 2.9257 \\
\hline Th-232 & 4.755 & 8.030 & - \\
\hline
\end{tabular}

Table 3. Average energy of SF spectrum

\begin{tabular}{|c|c|c|c|c|}
\hline \multirow{2}{*}{ Nuclide } & \multicolumn{4}{|c|}{ Average energy of spectrum } \\
\cline { 2 - 5 } & NEDIS & SOURCES & {$[17]$} & Exp.[18,19] \\
\hline $\mathrm{U}-238$ & 2.001 & 1.688 & 2.014 & - \\
\hline $\mathrm{Pu}-240$ & 2.013 & 1.933 & 1.981 & $2.04 \pm 0.04$ \\
\hline $\mathrm{Cm}-248$ & 2.088 & 1.954 & - & $2.07 \pm 0.02$ \\
\hline $\mathrm{Cf}-252$ & 2.134 & 2.306 & 2.306 & $2.13 \pm 0.01$ \\
\hline Th-232 & 1.954 & 1.597 & - & - \\
\hline
\end{tabular}

\section{Results of calculation of neutron yields and energy spectra}

\section{1. ${ }^{227} \mathrm{Ac}-{ }^{13} \mathrm{C},{ }^{244} \mathrm{Cm}-{ }^{13} \mathrm{C}$ and ${ }^{210} \mathrm{Po}-{ }^{13} \mathrm{C}$ sources of neutrons}

Neutron spectral measurements have been reported [6] for two mixtures, one contains ${ }^{227} \mathrm{AcO}_{2}$ with daughter products and the second contains dioxide ${ }^{244} \mathrm{CmO}_{2}$ mixed with ${ }^{13} \mathrm{C}$ powder target material and [7] for ${ }^{210} \mathrm{Po}-{ }^{13} \mathrm{C}$ source of neutrons. The neutron yields calculated by NEDIS-2.0 are in satisfactory agreement with measurements for radius of ${ }^{227} \mathrm{AcO}_{2} \sim 1 \mu \mathrm{m}$ and radius of ${ }^{244} \mathrm{CmO}_{2} \sim 12.8 \mu \mathrm{m}$. The spectra calculated by NEDIS-2.0 and measured in [6,7] are presented in Fig.1, Fig.2, and in Fig 3. Discrepancies in spectra are expected due to slowing-down of the neutrons in encapsulated sources and in the detector.

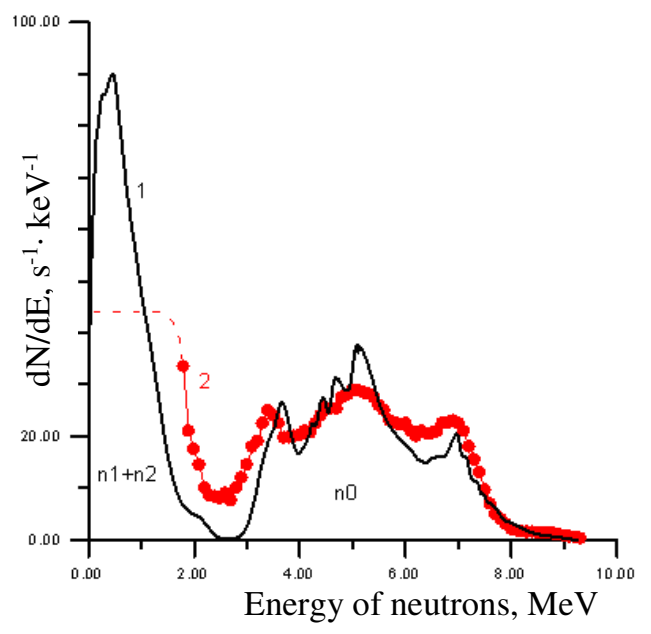

Fig. $1-{ }^{227} \mathrm{Ac}-{ }^{13} \mathrm{C}$ neutron spectra (1-calculated by NEDIS-2.0, 2 - measured)

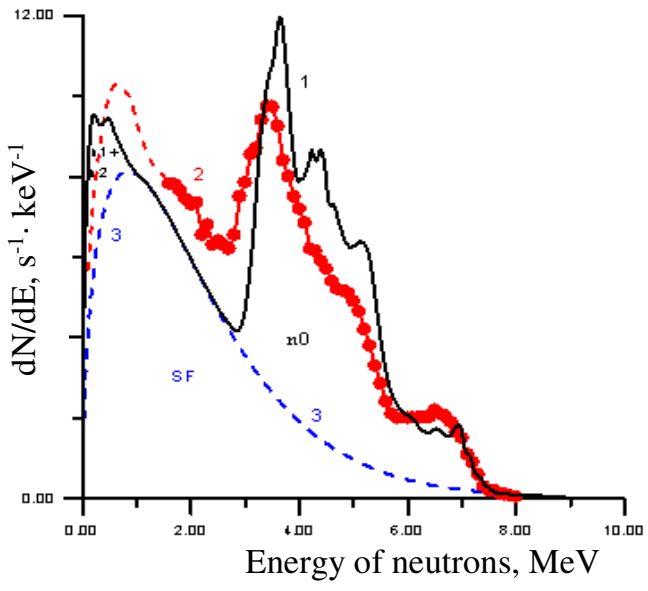

Fig. 2 - ${ }^{244} \mathrm{Cm}-{ }^{13} \mathrm{C}$ neutron spectra (1-calculated by NEDIS-2.0, 2 - measured, 3 - spontaneous fission spectrum)

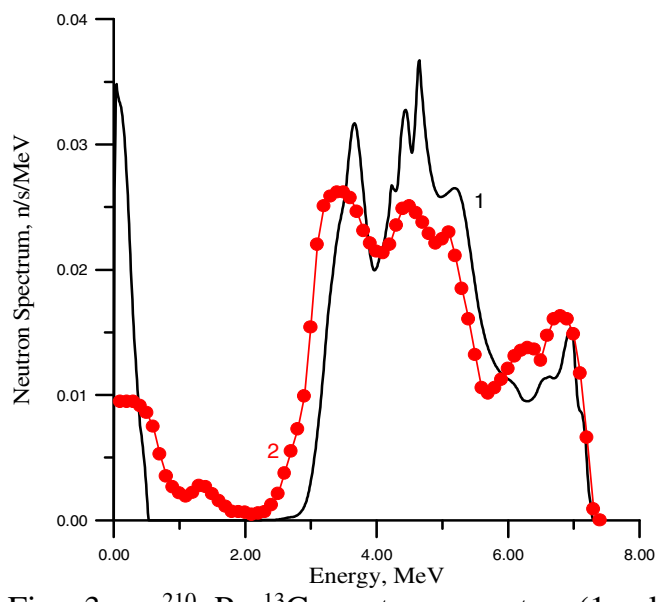

Fig. $3-{ }^{210} \mathrm{Po}^{13} \mathrm{C}$ neutron spectra (1-calculated by NEDIS-2.0, 2 - measured [7] ) 


\section{2 ${ }^{241} \mathrm{Am}(\mathrm{Au})-{ }^{13} \mathrm{C}$ plane source of neutrons for calibration in Daya Bay experiment}

The NEDIS2.0 has been used to calculate the neutron yield and spectra from the source [8]. $\mathrm{P}\left(\mathrm{E}_{\alpha}\right)$ - the number of $\alpha$-particles with energy more than $E_{\alpha}$ was calculated in continuous-retardation approximation, neglecting fluctuations in the $\alpha$-particle energy loss due to scattering and inelastic collision in Am, in $1.1 \mu \mathrm{m}$ gold and ${ }^{13} \mathrm{C}$. Results are presented in Fig.4 and in Table 4, which are in agreement with an assay of [8].

\section{Rel.Units}

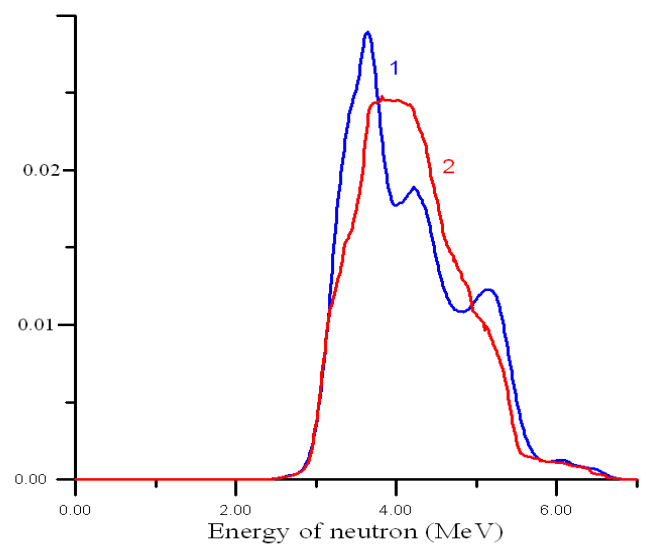

Fig. $4-{ }^{241} \mathrm{Am}(\mathrm{Au})-{ }^{13} \mathrm{C}$ neutron spectra (1-calculated by NEDIS-2.0, 2 -isotropic in CMS ( $\alpha, \mathrm{n}$ cross section from JENDL [20]).

Table 4. Neutron yields due to ${ }^{13} \mathrm{C}(\alpha, n){ }^{16} \mathrm{O}$ reaction.

\begin{tabular}{|c|c|c|c|c|}
\hline \multirow[b]{2}{*}{$\begin{array}{l}\text { Thickness } \\
\text { of }{ }^{241} \mathrm{Am} \\
\operatorname{disc}(\mu \mathrm{m})\end{array}$} & \multirow{2}{*}{$\begin{array}{l}\text { Deposit } \\
\text { thickness } \\
\text { of } \mathrm{Au} \\
(\mu \mathrm{m})\end{array}$} & \multicolumn{3}{|c|}{ Neutron yield $\left(\mathrm{s}^{-1}\right)$} \\
\hline & & $\begin{array}{c}\text { Ground of } \\
{ }^{16} \mathrm{O}\end{array}$ & $\begin{array}{c}1-\mathrm{st} \\
(6,049 \\
\mathrm{MeV})\end{array}$ & $\begin{array}{c}\text { 2-nd (6,13 } \\
\mathrm{MeV})\end{array}$ \\
\hline 1 & 0 & 3,62 & 0,400 & 0,048 \\
\hline 4 & 0 & 2,52 & 0,109 & 0,0124 \\
\hline 1 & 0,7 & 1,983 & $5,47 \mathrm{e}-03$ & $3,43 e-06$ \\
\hline 1 & 1 & 1,7 & $5,51 \mathrm{e}-07$ & 0,0 \\
\hline 1 & 1,1 & 1,622 & 0,0 & 0,0 \\
\hline 2 & 1 & 1,47 & $2,75 \mathrm{e}-07$ & 0,0 \\
\hline 3 & 1 & 1,28 & $1,84 \mathrm{e}-07$ & 0,0 \\
\hline 4 & 1 & 1,11 & $1,38 \mathrm{e}-07$ & 0,0 \\
\hline 4 & 1,1 & 1,056 & 0,0 & 0,0 \\
\hline 5 & 1 & 0,955 & $1,10 \mathrm{e}-07$ & 0,0 \\
\hline
\end{tabular}

\subsection{Decay-induced neutrons}

Table 5 presents earlier values not updated in a longtime of the neutron yield per $10^{6} \alpha$-particle in the materials given by the experiments $[21,22]$ and presentday ones by the NEDIS code which assumes secular equilibrium in the decay chains of ${ }^{238} \mathrm{U}$ and ${ }^{232} \mathrm{Th}$. The results of calculation presented in the Table 5 are in satisfactory agreement with the measurements may be used to compare and benchmark new codes to estimate uncertainty of the $(\alpha, n)$ neutron yield calculations for a number of materials that are used and will be used for construction of dark matter detectors [14].
Table 5. Neutron yield (per $10^{6} \alpha$-particles) due to presence of ${ }^{238} \mathrm{U}$ and ${ }^{232} \mathrm{Th}$ in secular equilibrium [21,22].

\begin{tabular}{|c|c|c|c|c|}
\hline \multirow{2}{*}{ material } & \multicolumn{2}{|c|}{$\mathrm{U}-238$} & \multicolumn{2}{c|}{ Th-232 } \\
\cline { 2 - 5 } & $\begin{array}{c}\text { Measurem } \\
\text { ent }\end{array}$ & NEDIS & $\begin{array}{c}\text { Measurem } \\
\text { ent }\end{array}$ & NEDIS \\
\hline $\mathrm{Be}$ & $92 \pm 13$ & $79,6 \pm 2,4$ & $126 \pm 15$ & $118 \pm 3$ \\
\hline $\mathrm{BeO}$ & $33 \pm 4$ & $29,3 \pm 0,9$ & $47 \pm 5$ & $43,2 \pm 1,4$ \\
\hline $\mathrm{B}$ & $21 \pm 3$ & $19,1 \pm 0,8$ & $27 \pm 4$ & $25,1 \pm 1,1$ \\
\hline $\mathrm{H}_{3} \mathrm{BO}_{3}$ & $3,1 \pm 0,5$ & $3,25 \pm 0,12$ & - & $4,26 \pm 0,17$ \\
\hline $\mathrm{C}$ & $0,17 \pm 0,04$ & $0,14 \pm 0,01$ & $0,31 \pm 0,08$ & $0,23 \pm 0,01$ \\
\hline $\mathrm{CaF}_{2}$ & $7,0 \pm 2,2$ & $4,84 \pm 0,33$ & $11,2 \pm 3,2$ & $8,1 \pm 0,5$ \\
\hline $\mathrm{CaF}_{2}$ & $5,7 \pm 1,0$ & $4,84 \pm 0,33$ & $10,2 \pm 2,2$ & $8,1 \pm 0,5$ \\
\hline $\mathrm{NaF}$ & $6,8 \pm 2,1$ & $4,75 \pm 0,32$ & $12,7 \pm 4,5$ & $11,1 \pm 0,5$ \\
\hline $\mathrm{Na}_{2} \mathrm{CO} 3$ & $1,7 \pm 0,3$ & $1,44 \pm 0,14$ & $3,3 \pm 0,5$ & $2,93 \pm 0,3$ \\
\hline $\mathrm{Al}$ & $1,5 \pm 0,2$ & $1,52 \pm 0,05$ & $3,2 \pm 0,3$ & $3,3 \pm 0,1$ \\
\hline $\mathrm{Al}$ & $1,47 \pm 0,15$ & $1,52 \pm 0,05$ & $3,2 \pm 0,3$ & $3,3 \pm 0,1$ \\
\hline $\mathrm{Al}_{2} \mathrm{O} 3$ & $0,8 \pm 0,1$ & $0,78 \pm 0,04$ & $1,8 \pm 0,2$ & $1,67 \pm 0,08$ \\
\hline $\mathrm{Mg}$ & $2,1 \pm 0,4$ & $1,71 \pm 0,06$ & $3,6 \pm 0,5$ & $3,21 \pm 0,12$ \\
\hline $\mathrm{Mg}$ & $1,6 \pm 0,2$ & $1,71 \pm 0,06$ & $3,1 \pm 0,4$ & $3,21 \pm 0,12$ \\
\hline $\mathrm{SiO}_{2}$ & $0,13 \pm 0,02$ & $0,134 \pm 0,011$ & $0,27 \pm 0,05$ & $0,25 \pm 0,02$ \\
\hline $\mathrm{Si}$ & $0,26 \pm 0,06$ & $0,21 \pm 0,02$ & $0,51 \pm 0,11$ & $0,43 \pm 0,03$ \\
\hline $\mathrm{K}_{2} \mathrm{CO}_{3}$ & $0,12 \pm 0,03$ & $0,10 \pm 0,01$ & $0,25 \pm 0,06$ & $0,21 \pm 0,02$ \\
\hline
\end{tabular}

Neutron spectra due to presence of ${ }^{238} \mathrm{U}$ in secular equilibrium for $\mathrm{Li}, \mathrm{F}, \mathrm{O}, \mathrm{B}, \mathrm{C}$ and $\mathrm{Be}$ are presented in Fig.5.

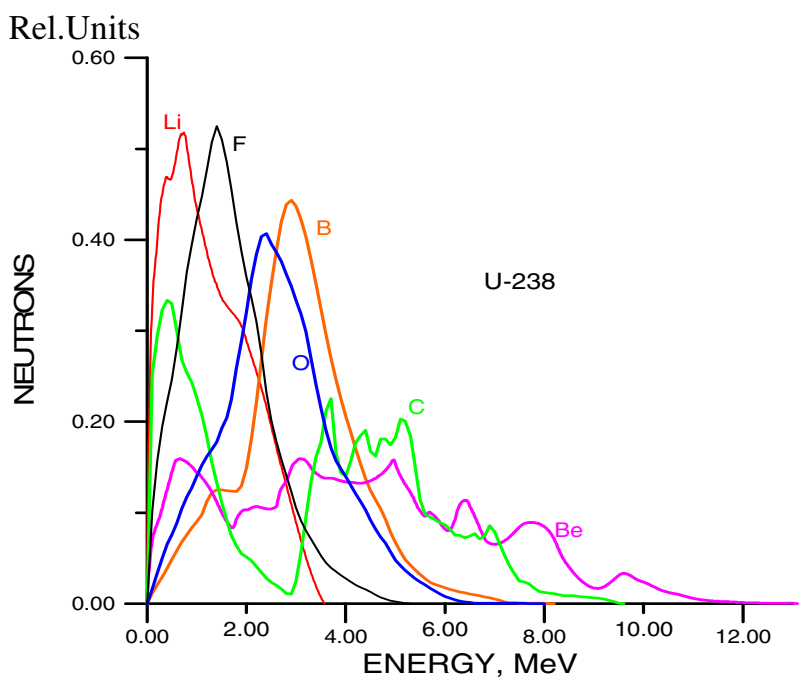

Fig. 5-Neutron spectra calculated by NEDIS-2.0.

\subsection{Plutonium oxide}

Measured total neutron yields from five plutonium oxide samples were collected in paper [23]. Two samples were measured at the Japan Atomic Energy Research Institute (JAERI) with using neutron coincidence counter and others at Oak Ridge National Laboratory (ORNL), Savannah River Plant (SRP), and at Pacific Northwest Laboratories (PNL). Results of calculations and measurements are given in Table 6. Measured and calculated neutron yields are in satisfactory agreement. 
Table 6. Calculated and measured source magnitudes for several plutonium oxide samples

\begin{tabular}{|c|c|c|c|}
\hline \multirow{2}{*}{ SAMPLE } & \multicolumn{3}{|c|}{ NEUTRONS/S } \\
\cline { 2 - 4 } & MEASURED & SOURCES & NEDIS-2.0 \\
\hline JAERI-1 & $\mathrm{sf}(184.7 \pm 4.8)$ & 215 & 209.5 \\
\hline & $\alpha, \mathrm{n}(157.8 \pm 9.8)$ & 138 & 135.5 \\
\hline & tot $(342.6 \pm 8.6)$ & 353 & 345 \\
\hline JAERI-2 & sf $(42.1 \pm 1.1)$ & 48 & 46.4 \\
\hline & $\alpha, \mathrm{n}(51.3 \pm 2.5)$ & 54 & 54.3 \\
\hline ORNL & tot $(93.4 \pm 2.3)$ & 102 & 100.7 \\
\hline SRP & $(868 \pm 9) 10^{2}$ & $85310^{2}$ & $83410^{2}$ \\
\hline$P N L$ & $2.310^{5}$ & $2.3910^{5}$ & $2.3410^{5}$ \\
\hline
\end{tabular}

\subsection{Borosilicate glass}

The total neutron emission has been measured [24] at the Savanna River Laboratory from three glass samples doped with $\mathrm{PuO}_{2}$ where mass fraction of ${ }^{238} \mathrm{Pu} \sim 90 \%$. The results of measurements are compared with calculated neutron yields using NEDIS-2.0 and ORIGEN-S [25] codes in Table 7.

Table 7. Borosilicate glass results of emission rate

\begin{tabular}{|c|c|c|c|c|}
\hline \multirow{2}{*}{$\begin{array}{c}\text { GLASS } \\
\text { SAMPLE }\end{array}$} & \multirow{2}{*}{$\begin{array}{c}\text { MASS } \\
\text { OF } \\
\text { PU-238 } \\
\text { (mg) }\end{array}$} & \multicolumn{3}{|c|}{ NEUTRONS/S } \\
\hline & & MEASURED & ORIGEN-S & $\begin{array}{c}\text { NEDIS- } \\
2.0\end{array}$ \\
\hline 1 & 10.8 & 4810 & 5571 & 5682 \\
\hline 2 & 1.03 & 473 & 532 & 542 \\
\hline 3 & 0.364 & 170 & 188 & 192 \\
\hline
\end{tabular}

It was noted in [24] the uncertainty in the content of ${ }^{238} \mathrm{Pu}$ in the glass was about $5 \%$ and yields may be underestimated by as much as $10 \%$ due to the calibration with ${ }^{252} \mathrm{Cf}$ source (spectral differences). However, the dimensions of particles of $\mathrm{PuO}_{2}$ in glass may be $\sim 0.1-5$ $\mu \mathrm{m}$ [26]. For $1.5 \mu \mathrm{m}$ radius of particles NEDIS-2.0 outputs 4970, 474, $168 \mathrm{n} / \mathrm{s}$ and agreement with the measurements are $\sim 3 \%$. The predicted neutron source spectra from the glass sample 1 are illustrated in Fig.6.

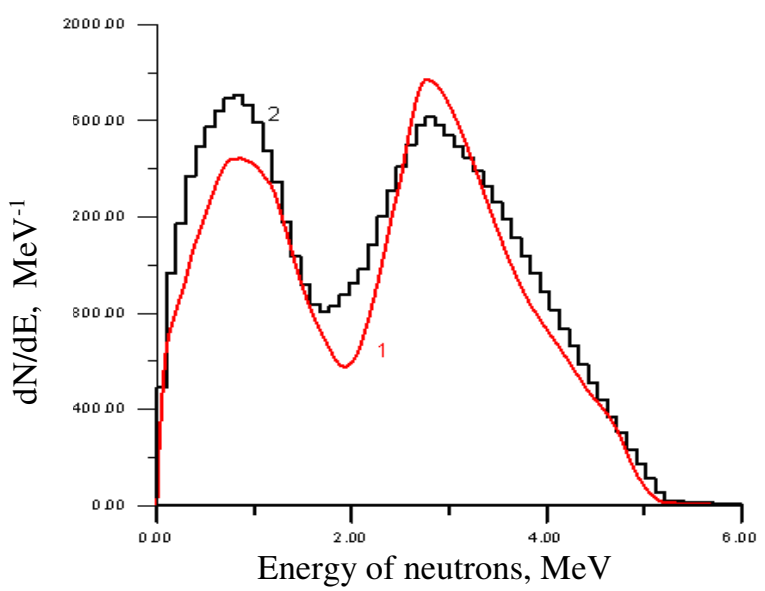

Fig. 6 - Energy dependent neutron source strength in glass sample 1 as calculated by 1-NEDIS-2.0 with account for radius of $\mathrm{PuO}_{2}$ particles and 2- ORIGEN-S .

\section{Conclusions}

There is a growing need for high-accuracy $(\alpha, n)$ yields and spectra from compounds of actinides and light elements in different nuclear technology mediums (as an example $\mathrm{LiCl}+\mathrm{KCl}$ ) due to interest in using neutron measurements for nuclear fuel fabrication and reprocessing plant safeguards and nuclear material accountancy. Improving these calculations will ultimately help safeguards professionals make better measurements with fewer resources. More broadly, computer codes such as MCNP are now being used to simulate shielding, require accurate continuous neutron spectrum and magnitude as input. The availability of accurate data is critical in these scenarios. The code NEDIS-2.0 is a useful and flexible computational tool for the accurate analysis of neutron emission rates and energy spectra of different materials of nuclear fuel cycle.

\section{References}

1. G.N. Vlaskin, E.V. Chvankin, Neutron spectrum and yield of accompanying photon radiation of lithium neutron sources. Sov. At. Energy 74, 129134, 1993.

2. G. N. Vlaskin, "NEDIS2.0 code to calculate yields and spectra of neutrons produced in light element nuclei $(\alpha, n)$ reactions and spontaneous fission", Preprint VNIINM 06-1, 2006.

3. G.N.Vlaskin, Yu.S.Khomyakov, V.I.Bulanenko, Neutron Yield of the Reaction $(\alpha, n)$ on thick Targets comprised of Light Elements. Atomic Energy, Vol.117, No. 5, March, 2015 (Russian Original Vol.117,No. 5, November, 2014, pp. 287 293)

4. D. West, A.C. Sherwood. Measurements of ThickTarget $(\alpha, n)$ Yields from Light Elements, Ann. Nucl. Enegy, Vol. 9, pp. 551-577, 1982.

5. G.J.H. Jacobs, H. Liskien, Energy Spectra of Neutrons Produced by $\alpha$-Particles in Thick Targets of Light Elements, Ann. Nucl. Enegy, Vol.10, pp. 541-552, 1983.

6. K.W. Geiger, L. Van-der-Zwan. Neutrons and $\gamma$ Rays from Radioactive ${ }^{13} \mathrm{C}(\alpha, \mathrm{n})$ sources, Nucl. Instr. Meth., 1978, Vol. 157, p. 199-201.

7. A.A.Chudotvortsev et.al., Energy spectrum of neutron and gamma radiation $(\alpha, n)$-sources on ${ }^{13} \mathrm{C}$, ${ }^{18} \mathrm{O},{ }^{25} \mathrm{Mg}$. In book: Radiation Technique, V.18, M., Atomiztad,1978, p. 35.

8. J. Liu et al. , Neutron calibration sources in DayaBay experiment. Nuclear Instruments and Methods in Physics Research A 797 (2015) 260-264

9. J. Ziegler, Helium: Stopping Powers and Ranges in All Elements, Pergamon Press, New York (1977).

10. B. G. Whitmore and W. B. Baker, "The Energy Spectrum of Neutrons from a Po-Be Source", Phys. Rev., 114, pp. 571-577(1959).

11. M. Berglund and M. Wieser, Isotopic Composition of the Elements 2009, (IUPAC Technical Report) Pure Appl. Chem. Vol.83, No.2, pp. 397-410, 2011

12. M.Abramovitz and I.Stegun(1974), Handbook of 
Mathematical Functions (Dover, New York).

13. W.B. Wilson, R.T. Perry, W.S. Charlton, T.A. Parish and E.F. Shores, SOURCES: A code for calculating (alpha,n), spontaneous fission, and delayed neutron sources and spectra, Radiation Protection Dosimetry 115 (2005) 117-121.

14. D.-M. Mei, C. Zhang and A. Hime, Evaluation of $(\alpha, n)$ induced neutrons as a background for dark matter experiments, Nuclear Instruments and Methods $\quad$ A $\quad \mathbf{6 0 6} \quad$ (2009)651-660. doi:10.1016/j.nima. 2009.04.032. Data available at http://neutronyield.usd.edu

15. S. Simakov, M. Verpelli, N. Otsuka. Update of the nuclear data for the neutron emissions for actinides of interest in safeguards. NDS, IAEA, 2015

16. J. Terrell, "Fission Neutron Spectra and Nuclear Temperatures", Phys. Rev. 113, pp. 527-541(1959).

17. D.G. Madland, "Calculation of Watt Distribution Parameters for Spontaneous and Neutron-Induced Fission," in Los Alamos National Laboratory report LA-8757-PR, p. 17 (March 1981).

18. V. Kalinin, V. Dushin, F.J.O. Hambsch, et al. Measurements of Prompt Neutron Multiplicity Distributions in Correlation with Mass-Energy Distribution of Fission Fragments in Spontaneous Fission of ${ }^{252} \mathrm{Cf},{ }^{244} \mathrm{Cm}$ and ${ }^{248} \mathrm{Cm}$., J.of Nucl.Sci. \&Techn.,Supl,2, Aug.,2002, Proc. Of Int. Conf. Nucl. Data for Sci. \&Tech. Tsukuba, Japan, 2001, p. 250-253.

19. B. Gerasimenko, L. Drapchinsky, O. Kostochkin et al. Precision Measurements of Prompt Neutron Spectra in ${ }^{240} \mathrm{Pu}$ and ${ }^{242} \mathrm{Pu}$ Spontaneous Fission., J. of Nucl. Sci. \&Techn.,Supl,2, Aug.,2002, Proc. Of Int. Conf. Nucl. Data for Sci. \&Tech. Tsukuba, Japan, 2001, p. 362-365.

20. Murata T., Matsunobu H., Shibata K. Evaluation of the $(\alpha, \mathrm{xn})$ Reaction data for JENDL/AN-2005, // JAEA-Research 2006-052, 2006.

21. G. V. Gorshkov,V. A. Zyabkin, N. M. Lyatkovskaya and O. S. Tsvetkov, Natural Neutron Background of the Atmosphere and Earth's Crust, Atomizdat, Moscow (1966).

22. Y. Feige, B. Oltman, and J. Kastner, "Production rates of neutrons in soils due to natural radioactivity," J. Geophys.Res., 73, 3135-3142 (1968).

23. E.F. Shores. Plutonium oxide benchmark problems for the SOURCES code. Appl. Radiat. and Isot. 62(2005), 669-704

24. D.J. Pellarin,W.L. Matney and Bibler. $(\alpha, n)$ Neutron Emission from DWPF Glass, DPST-86212, Memorandum to M.J. Plodinec, Savannah River Laboratory (1986)

25. I.G. Gauld, E.F. Shores, and R.T. Perry. New Neutron Source Algorithms in the ORIGEN-S code. In Proceeding of the $12^{\text {th }}$ Biennial Topical Meeting of the Radiation Protection and Shielding Division of the American Nuclear Society, Spokane, WA, 17-21 September 2000 (2000).

26. J.D. Vienna, D.L. Alexander, M.J. Schweiger, D.K. Peeler, T.F. Meaker. Plutonium Dioxide Dissolution in Glass, PNNL-11346, 1996. 